\title{
Youth proxy efficacy for fruit and vegetable availability varies by gender and socio-economic status
}

\author{
Karly S Geller ${ }^{1}$ and David A Dzewaltowski ${ }^{2, *}$ \\ ${ }^{1}$ Cancer Research Center of Hawaii, University of Hawaii at Manoa, Honolulu, Hawaii: ${ }^{2}$ Department of \\ Kinesiology and Community Health Institute, Natatorium 8, Kansas State University, Manhattan, KS 66506, USA
}

Submitted 17 March 2009: Accepted 23 November 2009: First published online 15 January 2010

\begin{abstract}
Objective: The current study examined proxy efficacy, which was defined as youth's confidence to influence their parents to provide fruits and vegetables. The overall objective was to examine change in middle-school youth's proxy efficacy over time, and to determine if changes were moderated by gender and socio-economic status.

Design: Longitudinal cohort nested within schools.

Setting: Eight middle schools located in urban, suburban and rural areas of a mid-western US state.

Subjects: Seven hundred and twelve youth followed across their 6th, 7th and 8th grade years. The sample was $51 \cdot 8 \%$ female, $30.5 \%$ low socio-economic status and $89 \cdot 5 \%$ Caucasian, non-Hispanic.

Results: Males and lower socio-economic status youth were significantly lower in proxy efficacy at each assessment year compared with females and high socioeconomic youth, respectively.

Conclusions: Proxy efficacy to influence parents to provide fruits and vegetables may be an important construct to target in future interventions.
\end{abstract}

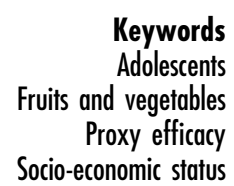

Keywords and vegetables

Socio-economic status
Youth fruit and vegetable consumption (FVC) in the USA is well below current guidelines. Surveillance research reports only $21 \%$ of adolescents consume five or more fruit and vegetable (FV) servings per day ${ }^{(1)}$ and only $1 \cdot 2 \%$ of boys and $3.6 \%$ of girls (9-13 years) consume the minimal amount of FV servings recommended by the Dietary Guidelines for Americans ${ }^{(2,3)}$. Additionally, FVC levels decline as children enter adolescence ${ }^{(4,5)}$ and, in comparison to their counterparts, inadequate FVC appears to be more prevalent among males ${ }^{(6,7)}$ and lower socio-economic status (SES) youth ${ }^{(5-8)}$. With additional consideration of strikingly rapid increases in adolescent obesity during the last 30 years ${ }^{(9,10)}$ and evidence supporting the role of FVC in obesity recovery and prevention $^{(11,12)}$, these inadequate levels of FVC illuminate a public health concern.

To intervene effectively and improve youth FVC, it is necessary for research to not only describe what influences youth FVC, but to extend efforts to address how; in other words, how can we maintain those influences in the youth environment to promote consistent FVC? To date, FV availability and FV preference emerge as the strongest and most consistent influences on youth FVC in bothcross sectional $^{(13-20)}$ and longitudinal studies ${ }^{(6,21)}$. Not surprisingly, FV availability is also reported to moderate changes in youth FV preference; thus, FV availability facilitates repeated exposure and is necessary to improve youth preferences for $\mathrm{FV}^{(13,14)}$. The primary need for availability is also consciously recognized by youth, with youth consistently reporting their food choices are less based on health and more on what is made available to them ${ }^{(22-25)}$. Taken together, the primary what seems to be FV availability, expanding to how promotion programmes can re-structure youth environments to improve FV availability. With environments that secure FV options for youth, the efficacy of future FV promotion programmes should increase, ultimately improving youth FV preference and consumption. This sounds ideal; however, the realization is that $\mathrm{FV}$ availability promotion efforts do not directly involve youth, leading to the critical addition of who.

Characteristically, youth are born vulnerable to the entities and environments surrounding them and remain at this mercy through adolescence, diluting environmental change efforts that solely target youth. Without direct control of the social and institutional practices that make FV available, youth are left reliant on adults to provide FV options. This suggests that direct promotion of youth FVC is likely a pointless endeavour without consideration of the entities ruling their environment. A significant influence on youth diet is their parent (i.e. who), managing most of their food opportunities and options. 
For instance, youth ability to make healthier choices is at the mercy of the food options brought home by their parent $^{(26)}$. In brief, parents provide the food environments that surround youth, providing meal and snack food availability and communicating health behaviours both verbally and non-verbally ${ }^{(27)}$.

To prematurely summarize, we have compiled evidence as to what (FV availability) and who (parents), leaving us to ponder how. Given parental control over youth food environments, their positive and consistent involvement during $\mathrm{FV}$ promotion may be a large contributor to programme success. In fact, solely parentbased interventions and solely child-based interventions rarely report meaningful effects on youth weight ${ }^{(28)}$. Unfortunately, previous youth health programmes attempting to include parents report variable and/or poor parent involvement ${ }^{(29-31)}$. In fact, health professionals reported that lack of parental involvement was one of the strongest barriers to managing child obesity ${ }^{(32)}$. Given the barrier to direct parental participation, another potential route is the indirect promotion of their involvement through child empowerment.

Social cognitive theory is a predominant model to understand heath behaviour change, including a child empowerment approach, proxy efficacy. Proxy efficacy, or one's confidence that one can get others to act on one's behalf to reach a desired outcome ${ }^{(33)}$, is a process of behaviour change that empowers youth with the confidence to adopt personal responsibility for their health through repeated requests for healthier options and/or opportunities. We are all witness to the successful media strategies that exclude FV promotion ${ }^{(34)}$, create brand images for unhealthy foods recognizable by children as young as 2 years ${ }^{(35)}$ and have youth 'nagging' their parents at the grocery store for strategically placed energydense foods ${ }^{(36,37)}$. Why not mirror these ruthless tactics that create obesogenic environments and undermine our costly efforts? One cost-efficient tactic is to improve youth proxy efficacy. For example, programmes target youth proxy efficacy by advancing their awareness and value for their own health (especially FVC) and building their capacity to influence parental provision of FV availability. This approach aims to reach parents and promote healthy environmental changes through youth empowerment, facilitating a possible solution to bow.

The proxy construct has been studied minimally for FV availability, and there is no current research investigating this construct over time. Direct examinations of this construct report strong factorial validity ${ }^{(38,39)}$ and significantly lower proxy efficacy for parent-provided FV availability among youth attending low-SES schools compared with high-SES schools ${ }^{(39)}$. In FVC research, increases in cognitive/behavioural skills for FV availability ('asking skills') were related to improved self-efficacy, which resulted in increased $\mathrm{FVC}^{(40)}$. Similarly, Young and colleagues $^{(41)}$ found that youth who perceived parental support consumed more FV. Thus, positive changes may be possible by increasing youth confidence to request $\mathrm{FV}$ availability from their parent and should be examined with consideration for differing demographic characteristics.

The primary aim of the current study was to investigate youth proxy efficacy to influence their parents for FV availability. Using longitudinal data collected over three years (6th, 7th and 8th grade), the study investigated the development of proxy efficacy over the middle school years. The secondary aim was to examine the influence of youth-level demographic variables on youth proxy efficacy over time, specifically investigating the influence of gender (male, female) and SES (lower, higher). Considering the lack of previous proxy efficacy examinations, our hypotheses are generated from evidence reporting the prevalence of youth FVC. Thus, youth proxy efficacy was hypothesized to decline linearly over time and be lower among males and youth categorized as lower SES (i.e. receiving free or reduced-price school meals).

\section{Experimental methods}

\section{Participants and setting}

Participants were recruited from eight middle schools located in urban, suburban and rural areas of Kansas that were randomly selected as the control sites for the Healthy Youth Places (HYP) project. The HYP project was a longitudinal randomized control trial (sixteen schools in total; $50 \%$ control), targeting environmental change to promote healthy nutrition and physical activity among young adolescents (6th to 8th grade) ${ }^{(42,43)}$. The current analysis examines survey responses given by youth within the control condition of HYP ( $n$ 1506). Among those youth, 712 (47\%) had both complete demographic data and proxy scores for the 6th and 8th grade assessment points. Missing response scores for proxy items in 7 th grade (12\% missingness for each item) were estimated from 6th and 8th grade values using full-information maximum likelihood (FIML). FIML estimation is generally regarded as the best method for handling missing data in most confirmatory factor analysis (CFA) and structural equation modelling applications ${ }^{(44,45)}$. Of the 712 youth (mean age $12 \cdot 4$ years in 6th grade), $51 \cdot 8 \%$ of the sample was female, $30 \cdot 5 \%$ of the youth were classified as low SES (i.e. receiving free or reduced meal programme assistance) and $89 \cdot 5 \%$ were Caucasian, nonHispanic.

\section{Measures \\ Youth proxy efficacy was measured on a 6-point Likert scale, indicating youth confidence to influence their parent(s) to make fruits, vegetables and fruit juices available in their school lunch, including: (i) 'How sure}


are you that you can get your parents to help you include your favourite fruits in your lunch?'; (ii) 'How sure are you that you can get your parents to help you include cut-up vegetables with dressing (like carrot sticks and ranch dressing) in your lunch?'; (iii) 'How sure are you that you can get your parents to help you include $100 \%$ fruit juice with your lunch instead of soda?' The reliability of the proxy efficacy scale was tested using Cronbach's alpha and demonstrated appropriate reliability each year, ranging from $0 \cdot 863$ to $0 \cdot 933$.

\section{Data analyses}

The factor structure of proxy efficacy was first examined for measurement equivalence/invariance (ME/I) across time and between demographic subgroups, which should precede applications of LGM procedures ${ }^{(46,47)}$. Following confirmation of measurement invariance, latent growth modelling (LGM) analyses were conducted, which included a multiple indicators, multiple causes (MIMC) model $^{(48,49)}$ to examine the impact of youth-level demographic variables on proxy efficacy over time. All analyses were performed using Mplus 4.2 $2^{(50)}$.

\section{Longitudinal and group invariance}

Tests of measurement invariance provided information about the stability of proxy efficacy across gender, SES and time. Figure 1 illustrates the specified latent growth model (LGM). The model for the proxy efficacy latent factor included three indicator items, which contained no cross-loading across assessment years. The first indicator of proxy efficacy was used as a marker indicator for each assessment year. The measurement error terms were allowed to covary due to the expectation that some systematic variance unaccounted for by proxy efficacy was the same over time. Accordingly, the model was overidentified with twenty-three degrees of freedom.

All youth scores were included to examine longitudinal $\mathrm{ME} / \mathrm{I}$ across 6th, 7th and 8th grade, including equivalent tests for form, item loadings and intercepts. Group ME/I was examined at each time point using multi-group CFA for gender (female, male) and SES (lower, higher) subgroups. Due to the inflation of $\chi^{2}$ values as sample sizes increase and the unequal $n$ between both subgroups, random samples were drawn for male and lower-SES youth to match the sample size of their counterpart subgroup. Similar to longitudinal ME/I, group ME/I examinations included tests for equal form, item loadings and intercepts.

Longitudinal and group ME/I was examined with a multi-step approach, involving three nested CFA. For group ME/I, the validity of the factor structure was initially tested by examining the model separately for each subgroup. Next, sequential model constraints were imposed, examining ME/I of model form, factor loadings and item thresholds longitudinally, as well as across gender and SES subgroups. Form and factor loading

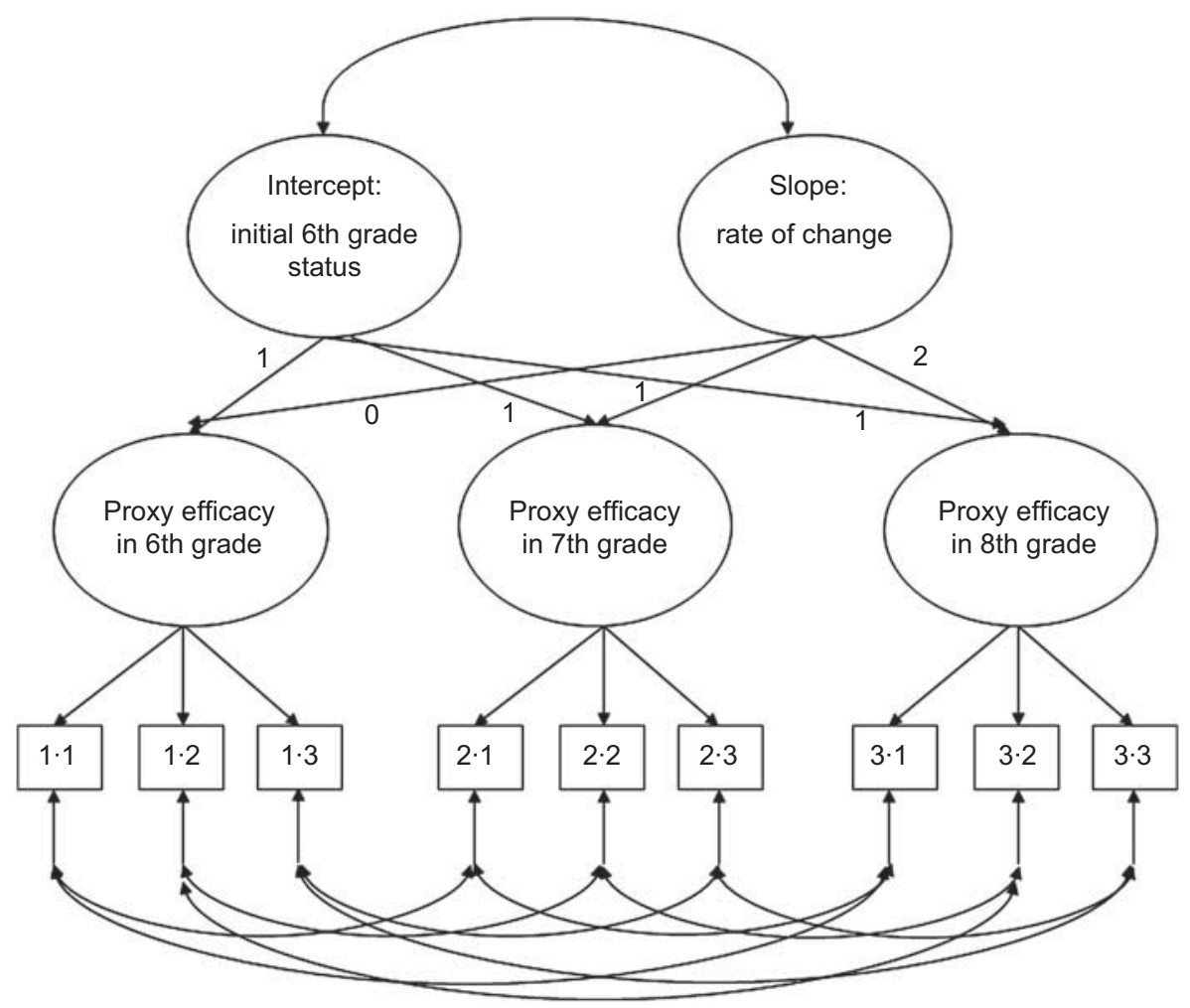

Fig. 1 Specified latent growth model for youth proxy efficacy from their parent for fruit and vegetable availability across the 6th, 7th and 8th grade 
equivalence is the minimal evidence necessary to establish ME/I, with further tests (i.e. equal thresholds) providing additional evidence ${ }^{(51)}$

Multiple indicators, multiple causes latent growth model LGM analysis is essentially a multilevel model for change; applying CFA to variables measured longitudinally ${ }^{(52)}$ to examine the level of proxy efficacy at each grade (intercept) and its rate of change over time (slope). The intercept was tested separately for each assessment year, while the slope was examined by assigning a regression weight to proxy efficacy at each of the three time points (i.e. 6 th grade $=0,7$ th grade $=1$, 8 th grade $=2$ ). Youth were nested within eight schools; thus, school was included in the model as a cluster variable, adjusting the standard errors of parameter estimates for potential between-school variability.

MIMC modelling included the simultaneous inclusion of youth-level covariates (gender, SES) to examine potential direct effects on the intercept and slope. A significant direct effect indicates different proxy efficacy means at different levels of the covariate; thus, results are interpreted based on the dummy code assigned to each covariate and the negative or positive sign of the parameter estimate. Given that females and higher-SES youth were dummy coded as 1 (their counterparts as 0 ), a positive parameter estimate would indicate higher values for these youth. MIMC modelling was chosen over multigroups CFA due to unequal subgroups $(n)$ and a less cumbersome application ${ }^{(53)}$.

\section{Model fit}

In addition to the $\chi^{2}$ statistic $^{(54)}$ model fit was assessed with multiple indices. The comparative fit index (CFI) was adequate at values above $0 \cdot 90^{(55)}$ and the Tucker-Lewis coefficient (TLI) ${ }^{(56)}$ at values greater than or equal to $0 \cdot 95^{(57)}$.
Root-mean-square error of approximation (RMSEA) values of less than 0.08 and less than 0.06 (and the 90\% confidence interval) indicated acceptable and close fit, respectively ${ }^{(58)}$. The standardized root-mean-square error (SRMR) reflected good fit at values less than $0 \cdot 08^{(59)}$. Finally, significance of factor loadings and modification indices were closely examined.

\section{Results}

\section{Longitudinal and group invariance}

Longitudinal and group ME/I results are presented in Table 1 , including $\chi^{2}$ and all model fit statistics. Longitudinal ME/I for form demonstrated viability of the proxy measurement model at all three assessment periods, such that each fit index was within the appropriate range, there existed no areas of strain (e.g. all modification index (MI) values $<3.5$ ), and all items were significantly (all $P<0 \cdot 001)$ and strongly related $\left(R^{2}\right.$ ranged from 0.575 to $0 \cdot 884)$ to proxy efficacy. In addition, correlations between proxy factors (i.e. stability coefficients) were significant between each assessment year, ranging from $0 \cdot 36$ to 0.50 (all $P<0 \cdot 05$ ).

Following baseline model assessment, a series of nested model comparisons with sequential equality constraints were examined for longitudinal ME/I. First, the meaning and structure of the proxy scale over time was confirmed equivalent (i.e. factor loadings), demonstrating appropriate fit indices without degrading model fit, $\chi_{\text {diff }}^{2}(4)=3 \times 637$, NS (critical value of $\chi^{2}(4)=9 \cdot 49$, $\alpha=0 \cdot 05$ ). However, additional model constraints specifying equal thresholds over time did degrade model fit, $\chi_{\text {diff }}^{2}(6)=23 \cdot 387$, NS (critical value of $\chi^{2}(6)=12 \cdot 59$, $\alpha=0 \cdot 05)$. To identify the unequal intercept(s), equality constraints with the highest MI values were consequently freed until model fit was appropriate. The intercept of the

Table 1 Longitudinal and group measurement invariance for proxy efficacy from parent(s) for fruit and vegetable availability (longitudinal $n$ 712; gender $n 340$ (50\% female); SES $n 216$ (50\% high))

\begin{tabular}{|c|c|c|c|c|c|c|c|c|c|c|c|c|}
\hline & & $x^{2}$ & df & $P$ value & $\chi_{\text {diff }}^{2}$ & $\Delta \mathrm{df}$ & RMSEA & $90 \% \mathrm{Cl}$ & CFitt & SRMR & CFI & TLI \\
\hline \multirow[t]{4}{*}{ Longitudinal invariance } & Form & $13 \cdot 889$ & 15 & 0.534 & & & 0.000 & $0.000,0.033$ & 0.999 & 0.011 & $1 \cdot 000$ & $1 \cdot 000$ \\
\hline & Loadings & $17 \cdot 526$ & 19 & 0.554 & $3 \cdot 637$ & 4 & 0.000 & $0.000,0.030$ & $1 \cdot 000$ & 0.015 & $1 \cdot 000$ & 1.000 \\
\hline & Intercepts & $40 \cdot 913$ & 25 & 0.023 & $23 \cdot 387^{\star}$ & 6 & $0 \cdot 300$ & $0.011,0.046$ & 0.983 & 0.020 & 0.996 & 0.995 \\
\hline & Partial intercepts & $22 \cdot 634$ & 24 & 0.542 & $5 \cdot 109$ & 5 & 0.000 & $0.000,0.028$ & $1 \cdot 000$ & 0.020 & $1 \cdot 000$ & $1 \cdot 000$ \\
\hline \multirow[t]{5}{*}{ Gender invariance } & Female & $25 \cdot 632$ & 24 & 0.372 & & & 0.014 & $0.000,0.047$ & 0.967 & 0.030 & 0.999 & 0.999 \\
\hline & Male & $21 \cdot 546$ & 24 & 0.606 & & & 0.000 & $0.000,0.039$ & 0.991 & 0.024 & $1 \cdot 000$ & $1 \cdot 000$ \\
\hline & Form & $51 \cdot 492$ & 45 & 0.235 & & & 0.021 & $0.000,0.043$ & & 0.028 & 0.998 & 0.998 \\
\hline & Loadings & $55 \cdot 879$ & 51 & $0 \cdot 297$ & $4 \cdot 387$ & 6 & 0.017 & $0.000,0.040$ & & 0.028 & 0.999 & 0.998 \\
\hline & Intercepts & $69 \cdot 198$ & 54 & $0 \cdot 800$ & $13 \cdot 319$ & 3 & 0.029 & $0.000,0.047$ & & 0.079 & 0.996 & 0.995 \\
\hline \multirow[t]{5}{*}{ SES invariance } & High & $14 \cdot 605$ & 24 & 0.932 & & & 0.000 & $0.000,0.016$ & 0.998 & 0.023 & $1 \cdot 000$ & $1 \cdot 000$ \\
\hline & Low & $15 \cdot 479$ & 24 & 0.906 & & & 0.000 & $0.000,0.023$ & 0.996 & 0.035 & $1 \cdot 000$ & $1 \cdot 000$ \\
\hline & Form & $32 \cdot 415$ & 45 & 0.920 & & & 0.000 & $0.000,0.016$ & & 0.024 & $1 \cdot 000$ & $1 \cdot 000$ \\
\hline & Loadings & $37 \cdot 417$ & 51 & 0.922 & $5 \cdot 002$ & 6 & 0.000 & $0.000,0.015$ & & 0.030 & $1 \cdot 000$ & $1 \cdot 000$ \\
\hline & Intercepts & $38 \cdot 726$ & 54 & 0.942 & $1 \cdot 309$ & 3 & 0.000 & $0.000,0.009$ & & 0.041 & $1 \cdot 000$ & 1.000 \\
\hline
\end{tabular}

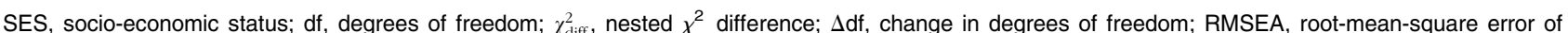
approximation; CI, confidence interval for RMSEA; CFit, test of close fit (probability RMSEA $\leq 0.05$ ); SRMR, standardized root-mean-square residual; CFI, comparative fit index; TLI, Tucker-Lewis index.

${ }^{\star}$ Significantly degrades the model $(P<0.001)$.

tMplus does not provide Cfit statistics for multiple-group confirmatory factor analysis. 
Table 2 MIMC LGM examining youth-level covariate effects on proxy efficacy from 6th to 8th grade and the rate of change in proxy efficacy over time ( $n$ 712; gender: female $n$ 372, male $n$ 340; SES: high $n 496$, low $n 216$ )

\begin{tabular}{|c|c|c|c|c|c|c|c|c|c|c|}
\hline Proxy efficacy & Covariate & Mean & SD & Skewness & Kurtosis & Un-Std Est & SE & Est/sE & Latent Std Est & Latent \& Item Std Est \\
\hline \multirow[t]{2}{*}{6 th grade } & Female & $4 \cdot 76$ & $1 \cdot 41$ & $-1 \cdot 11$ & 0.21 & $0 \cdot 48$ & $0 \cdot 11$ & $4 \cdot 22^{*}$ & 0.44 & $0 \cdot 22$ \\
\hline & Male & $4 \cdot 25$ & 1.63 & -0.66 & $-0 \cdot 81$ & & & & & \\
\hline \multirow[t]{2}{*}{ 7th grade } & Female & $4 \cdot 70$ & $1 \cdot 42$ & $-1 \cdot 10$ & $0 \cdot 37$ & 0.45 & $0 \cdot 10$ & $4 \cdot 58^{\star}$ & 0.50 & 0.25 \\
\hline & Male & $4 \cdot 26$ & 1.60 & -0.67 & -0.64 & & & & & \\
\hline \multirow[t]{2}{*}{ 8th grade } & Female & $4 \cdot 80$ & $1 \cdot 42$ & $-1 \cdot 27$ & $0 \cdot 81$ & 0.55 & $0 \cdot 14$ & $3 \cdot 98^{*}$ & $0 \cdot 46$ & $0 \cdot 23$ \\
\hline & Male & $4 \cdot 21$ & 1.72 & -0.59 & -0.96 & & & & & \\
\hline \multirow[t]{2}{*}{ Proxy $\Delta$} & Female & 0.05 & 0.26 & -0.20 & $1 \cdot 44$ & 0.04 & 0.09 & 0.407 & 0.07 & 0.036 \\
\hline & Male & -0.01 & 0.31 & -0.40 & 0.28 & & & & & \\
\hline \multirow[t]{2}{*}{6 th grade } & High SES & $4 \cdot 66$ & $1 \cdot 49$ & -1.09 & 0.15 & 0.52 & 0.12 & $4 \cdot 48^{*}$ & 0.48 & 0.22 \\
\hline & Low SES & $4 \cdot 18$ & $1 \cdot 61$ & -0.48 & -1.08 & & & & & \\
\hline \multirow[t]{2}{*}{ 7th grade } & High SES & $4 \cdot 63$ & $1 \cdot 46$ & $-1 \cdot 04$ & $0 \cdot 16$ & 0.51 & 0.13 & $3 \cdot 99^{*}$ & 0.55 & 0.25 \\
\hline & Low SES & $4 \cdot 17$ & $1 \cdot 60$ & -0.56 & $-0 \cdot 76$ & & & & & \\
\hline \multirow[t]{2}{*}{ 8th grade } & High SES & $4 \cdot 68$ & 1.52 & -1.09 & $0 \cdot 13$ & 0.59 & 0.22 & $2 \cdot 69^{*}$ & 0.49 & $0 \cdot 22$ \\
\hline & Low SES & $4 \cdot 13$ & 1.69 & -0.58 & -0.89 & & & & & \\
\hline \multirow[t]{2}{*}{ Proxy $\Delta$} & High SES & 0.03 & 0.28 & -0.41 & $1 \cdot 10$ & 0.03 & $0 \cdot 10$ & $0 \cdot 33$ & 0.06 & 0.028 \\
\hline & Low SES & -0.003 & 0.31 & -0.29 & 0.44 & & & & & \\
\hline
\end{tabular}

MIMC, multiple indicators, multiple causes; LGM, latent growth model; SES, socio-economic status; Un-Std, unstandardized; Est, estimate; Est/SE, critical value; Std, standardized; $\Delta$, change.

Binary values: females $=1$, males $=0$; high $S E S=1$, low $S E S=0$ (positive estimates reflect higher values for those coded 1 )

${ }^{\star} P<0.05$.

first proxy item in year three (p31) had the highest MI, which was released first leading to a non-significant change in model fit, $\chi_{\text {diff }}^{2}(5)=5 \cdot 109$, NS (critical value of $\left.\chi^{2}(5)=11 \cdot 07, \alpha=0 \cdot 05\right)$. Given invariant factor loadings over time, there is sufficient evidence for longitudinal $\mathrm{ME} / \mathrm{I}^{(51)}$; thus, the partially constrained model was tested further for group ME/I.

Table 1 presents results of subgroup comparisons. As seen, the baseline model fit each set of subgroup data well. In addition, all freely estimated factor loadings were statistically significant $(P<0 \cdot 05)$ and salient $\left(R^{2}>0 \cdot 40\right)$, demonstrating strong model consistency across youth gender and SES subgroups. Further tests confirmed equivalent form, factor loadings and item thresholds across both gender and SES subgroups (see Table 1). Evidence for longitudinal and group ME/I confirms the validity of the proxy scale across time and subgroup, assuring accuracy when examining longitudinal change in youth proxy, as well as potential variability based on youth-level gender and SES.

\section{Multiple indicators, multiple causes latent growth model}

Overall, the model presented a close fit to the data $\left(\chi^{2}(37)=39 \cdot 032, \quad P=0.379, \quad\right.$ CFI $=0.999, \quad$ TLI $=0.999$, RMSEA $=0 \cdot 009$, SRMR $=0 \cdot 019)$. The variance estimates for the intercept (1.069) and slope (0.272) were both statistically significant $(P<0 \cdot 05)$, as was the negative correlation between the intercept and slope $(r=-0 \cdot 378$, $P<0 \cdot 05$ ); thus, youth reporting higher proxy efficacy in 6th grade are less likely to decrease over time compared to youth with lower initial proxy. Table 2 provides indepth descriptive results for the proxy factor across time and between gender and SES subgroups. Results of the MIMC analysis are also presented in Table 2, including the unstandardized parameter estimates with standard errors and tests of significance. Also, the effect sizes presented in Table 2 are partially standardized; thus, only the latent variables have been modified to a standard scale, allowing the covariates to be expressed on the original metric. Given that gender and SES covariates are represented with dummy coded values (e.g. female $=1$, male $=0$ ), coefficient values are interpreted as the number of standardized scores proxy efficacy is predicted to change as a function of a change in the dummy coded metric (i.e. difference between males and females, difference between higher and lower SES). These standardized values can be interpreted analogous to Cohen's $d$ guidelines, such that $0 \cdot 20,0 \cdot 50$ and $0 \cdot 80$ represent small, medium and large effects, respectively ${ }^{(60,61)}$.

\section{Gender (females $=1$, males $=0$ )}

The unstandardized estimates of gender to proxy efficacy in 6th, 7th and 8th grade were all statistically significant. In 6th grade, females had significantly higher proxy efficacy scores compared with males, as reflected by a positive coefficient (females $+0 \cdot 48$ ). This difference was consistent in both 7 th (females +0.45 ) and 8 th grade (females $+0 \cdot 55$ ). The standardized effect size of these differences ranged from just short of moderate (6th and 8 th grade) to moderate in 7 th grade $(d=0 \cdot 50)$. The estimates from gender to the rate of change in proxy efficacy were not significant.

\section{Socio-economic status (higher $=1$, lower $=0$ )}

The unstandardized estimates of SES to proxy efficacy in 6th, 7 th and 8th grade were also all statistically significant. In 6th grade, the mean of high-SES youth was 0.52 units higher than the mean of low-SES youth, which remained consistent in both 7 th (higher SES +0.51 ) and 8 th grade 
(higher SES +0.59). The standardized effect size values ranged between 0.48 and 0.55 , indicating an average medium effect of youth SES on their proxy efficacy. Similar to gender, the estimates from SES to the rate of change in proxy efficacy over time were not significant.

\section{Discussion}

The present study examined the change in youth proxy efficacy to influence parents to provide FV across early adolescence (6th, 7th and 9th grade). In addition, the relationships between youth demographic variables (i.e. gender and SES) and youth proxy efficacy were examined over time. Below we review the study results in comparison with our study hypotheses.

First, the measurement scales demonstrated consistency over three years among youth developing through early adolescence. More specifically, both the factor structure and item loadings were equal and consistent over 6th, 7th, and 8th grade. Confirmed longitudinal ME/I ensures that differences found in proxy efficacy over time can be attributed to true change in the construct rather than shifts in the validity of the measure, strengthening results and offering a valid measure for future examinations.

Second, youth proxy efficacy did not change significantly over time, nor were there differences in proxy change based on gender or SES. This finding is contrary to our expectation of a linear decline over time, which would parallel evidence for the linear decline in youth FVC during this same period of development ${ }^{(4,5)}$. As children develop into adolescence they seek more independence and autonomy, which may lead to distancing in adolescent-parent relationships ${ }^{(62)}$; however, influences on FVC are similar between children and adolescents and parental influence remains significant throughout development ${ }^{(63,64)}$. Therefore, the consistency in proxy efficacy throughout early adolescence may reflect the ongoing role and influence of parents. Another potential explanation is the inclusion of grade levels that precede high school, representing young adolescents who are likely still dependent on communications with their parent. There were also no differences over time based on youth demographic characteristics, ruling out developmental distinctions in proxy efficacy between gender and SES subgroups. Interestingly, the variance of the slope (i.e. variability in proxy change) remained significant following inclusion of gender and SES as covariates, suggesting variability due to an unmeasured variable. It is probable that youth race/ethnicity contributes to this variability; however, due to a predominantly Caucasian sample, this type of analysis was not possible with the current data.

Third, within the current sample, differences in youth proxy efficacy for FV availability exist based on gender and SES. Relevant to gender, male youth expressed significantly lower proxy efficacy compared with females at 6th, 7th and 8th grade, which supports both our expectations and research reporting lower rates of FVC among boys ${ }^{(6,7)}$. Previous research has reported numerous gender differences regarding FV availability, such as: boys perceive less FV availability than $\operatorname{girls}^{(6)}$, boys' and parents' reports of FV availability are not consistent ${ }^{(6)}$ and FV availability is related to FVC among girls, but not boys ${ }^{(64)}$. These differences may be due to girls' exaggerated concern for health in comparison to boys ${ }^{(40)}$, leading to greater awareness of healthy food availability. Also, boys may care less about FV due to lower FV preferences $^{(6,14,65)}$. It may also be possible that lower proxy efficacy among boys for FV availability from their parent reflects advanced autonomy and/or detached parental relations. Further examinations of the proxy construct are required before conclusions can be made, including examining its relatedness to youth levels of FVC.

The current results also reflect significantly lower proxy efficacy among low-SES youth compared with high-SES youth at each assessment point, corresponding to our expectations, FVC research ${ }^{(5,7,8,66)}$ and similar investigations among children of elementary-school age ${ }^{(39)}$. There are numerous characteristics of low SES that may influence the youth food environment, including: longer parent working hours and less family time, lower family income, higher prevalence of single-parent homes, and lower awareness of healthy options and grocery stores access $^{(67,68)}$. It may be these characteristics, along with others, leading to lower FV availability ${ }^{(69)}$ and consumption among low-SES youth ${ }^{(5,70)}$, which may be related to lower proxy levels. However, without additional examinations, the factors contributing to these differences are still unknown. The most obvious possible contributor is family income, which was reported by both youth and parents to limit their food selection, cooking and eating practices $^{(71)}$. Thus, lower-SES youth may be aware of their family's economic struggle, which negatively impacts their proxy efficacy for FV availability.

There are specific strengths and limitations of the current study that should be noted. First, the LGM analyses included the entire measurement model, confirming the validity of results. A limitation of analyses completed with ordinary least squares (e.g. correlation analyses, multiple regression analyses) is the assumption that variables have been measured without error ${ }^{(53,59)}$. Another major strength of the included analyses is the comparison of proxy means across assessment years, as well as the rate of change over time. However, the low prevalence of diverse youth limited analyses, excluding assessment of variability based on race/ethnicity. In a recent focus group study, barriers and facilitators of FVC were found to vary between different racial/ethnic minority populations $^{(72)}$; thus, additional research on proxy efficacy is needed among a more diverse population. Another weakness is our categorization of youth SES solely based 
on lunch programme assistance status, possibly limiting the validity and generalizability of our results. Previous youth studies have used a variety of different measures to assess SES (i.e. maternal education, household income, etc.), making comparisons across studies difficult ${ }^{(73)}$ and possibility leading to inaccurate classifications ${ }^{(74,75)}$.

\section{Implications for research and practice}

Collectively, the present study provides novel information regarding youth proxy efficacy for FV availability and these findings may be useful in future intervention development. The influence of FV availability on youth consumption is supported in numerous research stu$\operatorname{dies}^{(6,13-16,21)}$, and we believe that empowering youth with the skills and confidence to request FV (i.e. proxy efficacy) may facilitate increased FV availability and consumption. There is some evidence that intervention strategies can build youth proxy to improve their physical activity opportunities and their physical activity levels ${ }^{(42,43)}$. Thus, similar future interventions may be able to reach parents by using youth proxy efficacy as a vehicle to promote healthy changes to the food environment. Our results also demonstrate differences in proxy efficacy based on gender and SES; however, the mechanisms linking these demographic characteristics to proxy efficacy are still unknown. Future research examining the intermediate variables between youth-level demographic variables and proxy efficacy are necessary.

\section{Acknowledgements}

All work was performed at the Department of Kinesiology and Community Health Institute, Kansas State University. The study was supported in part by RO1 HD37367 funded by the National Institute of Child Health and Human Development, the National Institute of Nursing Research, the Office of Disease Prevention, National Institute of Allergy and Infectious Diseases, and the Office of Dietary Supplements (NICHD, NINR, ODP, NIAID, ODS). There are no conflicts of interest. K.S.G. ran all statistical analysis and drafted the paper. D.A.D. was the principal investigator of the grant that supported this research and contributed to the writing and editing of the final manuscript.

\section{References}

1. Centers for Disease Control and Prevention (2008) Youth Risk Behavior Survey. Surveillance Summaries, 2007. MMWR 57(SS-4), 1-131.

2. US Department of Health and Human Services \& US Department of Agriculture (2005) Dietary Guidelines for Americans, 2005, 6th ed. Washington, DC: US Government Printing Office.

3. Guenther PM, Dodd KW, Reedy J et al. (2006) Most Americans eat much less than recommended amounts of fruits and vegetables. J Am Diet Assoc 106, 1371-1379.
4. Mensink GB, Kleiser C \& Richter A (2007) [Food consumption of children and adolescents in Germany. Results of the German Health Interview and Examination Survey for Children and Adolescents (KiGGS)]. Bundesgesundheitsblatt Gesundheitsforschung Gesundheitsschutz 50, 609-623.

5. Riediger ND, Shooshtari S \& Moghadasian MH (2007) The influence of sociodemographic factors on patterns of fruit and vegetable consumption in Canadian adolescents. $J \mathrm{Am}$ Diet Assoc 107, 1511-1518.

6. Bere E, Brug J \& Klepp KI (2008) Why do boys eat less fruit and vegetables than girls? Public Health Nutr 11, 321-325.

7. Lytle LA, Varnell S, Murray DM et al. (2003) Predicting adolescents' intake of fruits and vegetables. J Nutr Educ Behav 35, 170-175.

8. Rasmussen M, Krolner R, Klepp KI et al. (2006) Determinants of fruit and vegetable consumption among children and adolescents: a review of the literature. Part I: Quantitative studies. Int J Behav Nutr Phys Act 3, 22.

9. Ogden CL, Carroll MD, Curtin LR et al. (2006) Prevalence of overweight and obesity in the United States, 1999-2004. JAMA 295, 1549-1555.

10. Ogden CL, Flegal KM, Carroll MD et al. (2002) Prevalence and trends in overweight among US children and adolescents, 1999-2000. JAMA 288, 1728-1732.

11. Epstein LH, Paluch RA, Beecher MD et al. (2008) Increasing healthy eating vs. reducing high energy-dense foods to treat pediatric obesity. Obesity (Silver Spring) 16, 318-326.

12. Rolls BJ, Ello-Martin JA \& Tohill BC (2004) What can intervention studies tell us about the relationship between fruit and vegetable consumption and weight management? Nutr Rev 62, 1-17.

13. Baranowski T, Cullen KW \& Baranowski J (1999) Psychosocial correlates of dietary intake: advancing dietary intervention. Annu Rev Nutr 19, 17-40.

14. Cullen KW, Baranowski T, Owens E et al. (2003) Availability, accessibility, and preferences for fruit, 100\% fruit juice, and vegetables influence children's dietary behavior. Health Educ Behav 30, 615-626.

15. Hearn MD, Baranowski T, Baranowski J et al. (1998) Environmental influences on dietary behavior among children; availability and accessibility of fruits and vegetables enable consumption. J Health Educ 29, 26-32.

16. Kratt P, Reynolds K \& Shewchuk R (2000) The role of availability as a moderator of family fruit and vegetable consumption. Health Educ Behav 27, 471-482.

17. Woodward DR, Boon JA, Cumming FJ et al. (1996) Adolescents' reported usage of selected foods in relation to their perceptions and social norms for those foods. Appetite 27, 109-117.

18. Resnicow K, Davis-Hearn M, Smith M et al. (1997) Socialcognitive predictors of fruit and vegetable intake in children. Health Psychol 16, 272-276.

19. George RS \& Krondl M (1983) Perceptions and food use of adolescent boys and girls. Nutr Behav 1, 115-125.

20. Domel SB, Baranowski T, Davis HC et al. (1996) A measure of stages of change in fruit and vegetable consumption among fourth- and fifth-grade school children: reliability and validity. J Am Coll Nutr 15, 56-64.

21. Bere E \& Klepp KI (2005) Changes in accessibility and preferences predict children's future fruit and vegetable intake. Int J Behav Nutr Phys Act 2, 15.

22. Evans AE, Wilson DK, Buck J et al. (2006) Outcome expectations, barriers, and strategies for healthful eating: a perspective from adolescents from low-income families. Fam Community Health 29, 17-27.

23. Neumark-Sztainer D, Story M, Perry C et al. (1999) Factors influencing food choices of adolescents: findings from focus-group discussions with adolescents. J Am Diet Assoc 99, 929-937. 
24. O'Dea JA (2003) Why do kids eat healthful food? Perceived benefits of and barriers to healthful eating and physical activity among children and adolescents. I Am Diet Assoc 103, 497-501.

25. Story M, Neumark-Sztainer D \& French S (2002) Individual and environmental influences on adolescent eating behaviors. J Am Diet Assoc 102, 3 Suppl., S40-S51.

26. Domel SB, Thompson WO, Davis HC et al. (1996) Psychosocial predictors of fruit and vegetable consumption among elementary school children. Health Educ Res 11, 299-308.

27. Pearson N, Timperio A, Salmon J et al. (2009) Family influences on children's physical activity and fruit and vegetable consumption. Int I Behav Nutr Phys Act 6, 34.

28. Lindsay AC, Sussner KM, Kim J et al. (2006) The role of parents in preventing childhood obesity. Future Child 16, 169-186.

29. Coatsworth JD, Duncan LG, Pantin H et al. (2006) Retaining ethnic minority parents in a preventive intervention: the quality of group process. I Prim Prev 27, 367-389.

30. Nader PR, Sellers DE, Johnson CC et al. (1996) The effect of adult participation in a school-based family intervention to improve children's diet and physical activity: the Child and Adolescent Trial for Cardiovascular Health. Prev Med 25, 455-464.

31. Heinrichs N, Bertram H, Kuschel A et al. (2005) Parent recruitment and retention in a universal prevention program for child behavior and emotional problems: barriers to research and program participation. Prev Sci $\mathbf{6}$, 275-286.

32. Story MT, Neumark-Stzainer DR, Sherwood NE et al. (2002) Management of child and adolescent obesity: attitudes, barriers, skills, and training needs among health care professionals. Pediatrics 110, 210-214.

33. Bandura A (2001) Social cognitive theory: an agentic perspective. Annu Rev Psychol 52, 1-26.

34. Galo AE (1998) Food advertising in the United States. In America's Eating Habits: Changes and Consequences. Economic Research Service Report no. AIB-750, pp. 773-780 [E Frazao, editor]. Washington, DC: US Department of Agriculture.

35. Valkenburg PM \& Buijzen M (2005) Identifying determinants of young children's brand awareness: television, parents, and peers. I Appl Dev Psychol 26, 456-468.

36. Eisenberg D, McDowell J, Berestein L et al. (2002) It's an ad, ad, ad, ad world. Time 160, 38-42.

37. Dijksterhuis A, Smith PK, van Baaren RB et al. (2005) The unconscious consumer: effects of environment on consumer behavior. J Consum Psychol 15, 193-202.

38. Geller KS \& Dzewaltowski D (2009) Examining elementary school-aged children's self-efficacy and proxy efficacy for fruit and vegetable consumption. Health Educ Behav (Epublication ahead of print version).

39. Geller KS, Dzewaltowski DA, Rosenkranz RR et al. (2009) Measuring children's self-efficacy and proxy efficacy related to fruit and vegetable consumption. $J$ Sch Health 79, 51-57.

40. Reynolds KD, Yaroch AL, Franklin FA et al. (2002) Testing mediating variables in a school-based nutrition intervention program. Health Psychol 21, 51-60.

41. Young EM, Fors SW \& Hayes DM (2004) Associations between perceived parent behaviors and middle school student fruit and vegetable consumption. J Nutr Educ Behav 36, 2-8.

42. Dzewaltowski DA, Estabrooks PA \& Johnston JA (2002) Healthy youth places promoting nutrition and physical activity. Health Educ Res 17, 541-551.

43. Dzewaltowski DA, Estabrooks PA, Welk G et al. (2009) Healthy youth places: a randomized controlled trial to determine the effectiveness of facilitating adult and youth leaders to promote physical activity and fruit and vegetable consumption in middle schools. Health Educ Behav 36, 583-600.

44. Allison PD (2003) Missing data techniques for structural equation modeling. J Abnorm Psychol 112, 545-557.

45. Duncan TE \& Duncan SC (1998) A comparison of modeland multiple imputation-based approaches to longitudinal analysis with partial missingness. Structural Equ Modeling 5, 1-21.

46. Bollen KA \& Curran PJ (2004) Autoregressive latent trajectory (ALT) models: a synthesis of two traditions. Sociol Methods Res 32, 336-383.

47. Duncan TE, Duncan SC, Strycker LA et al. (1999) An Introduction to Latent Variable Growth Curve Modeling: Concepts, Issues, and Applications. Mahwah, NJ: Erlbaum.

48. Joreskog KG \& Goldberger AS (1975) Estimation of a model with multiple indicators and multiple causes of a single latent variable. J Am Stat Assoc 70, 631-639.

49. Muthen BO (1989) Latent variable modeling in heterogeneous populations. Psychometrika 54, 557-585.

50. Muthen LK \& Muthen BO (1998-2006) Statistical analysis with latent variables. In Mplus User's Guide: 4th Edition (Version 4.2). Los Angeles, CA: Muthen \& Muthen.

51. Marsh HW (1994) Confirmatory factor analysis models of factorial invariance: a multifaceted approach. Struct Equ Modeling 1, 5-34.

52. Singer JD \& Willet JB (2003) Applied Longitudinal Data Analysis: Modeling Change and Event Occurrence. New York: Oxford University Press.

53. Brown TA (2006) Confirmatory Factor Analysis for Applied Research. New York: The Guilford Press.

54. Bollen KA (1989) Structural Equations with Latent Variables. New York: John Wiley and Sons.

55. Bentler PM (1990) Comparative fit indexes in structural models. Psychol Bull 107, 238-246.

56. Bentler PM \& Bonett DG (1980) Significance tests and goodness of fit in the analysis of covariance structures. Psychol Bull 88, 588-606.

57. Hu L \& Bentler PM (1999) Cutoff criteria for fit indexes in covariance structure analysis: conventional criteria versus new alternatives. Struct Equ Modeling 6, 1-55.

58. Browne MW \& Cudeck R (1993) Alternate ways of assessing model fit. In Testing Structural Equation Models, pp. 136-162 [KA Bollen and JS Long, editors]. Newbury Park, CA: Sage.

59. Chan D (1998) The conceptualization and analysis of change over time: an integrative approach incorporating longitudinal means and covariance structures analysis (LMACS) and multiple indicator latent growth modeling (MLGM). Organ Res Methods 1, 421-483.

60. Cohen J (1988) Statistical Power Analysis for the Behavioral Sciences. Hillsdale, NJ: Erlbaum.

61. Cohen J (1992) A power primer. Psychol Bull 112, 155-159.

62. Committee on Community-Level Programs for Youth (2002) Community Programs to Promote Youth Development. Washington, DC: National Academy Press.

63. Geller KS \& Dzewaltowski DA (2009) Longitudinal and cross-sectional influences on youth fruit and vegetable consumption. Nutr Rev 67, 65-76.

64. Hanson NI, Neumark-Sztainer D, Eisenberg ME et al. (2005) Associations between parental report of the home food environment and adolescent intakes of fruits, vegetables and dairy foods. Public Health Nutr 8, 77-85.

65. Domel SB \& Thompson WO (2002) Fourth-grade children's consumption of fruit and vegetable items available as part of school lunches is related to preferences. J Nutr Educ Behav 24, 166-171.

66. Lien N, Jacobs DR Jr \& Klepp KI (2002) Exploring predictors of eating behaviour among adolescents by gender and socioeconomic status. Public Health Nutr 5, 671-681. 
67. Patrick H \& Nicklas TA (2005) A review of family and social determinants of children's eating patterns and diet quality. $J$ Am Coll Nutr 24, 83-92.

68. Schor EL (2003) Family pediatrics: report of the Task Force on the Family. Pediatrics 111, 1541-1571.

69. MacFarlane A, Crawford D, Ball K et al. (2007) Adolescent home food environments and socioeconomic position. Asia Pac J Clin Nutr 16, 748-756.

70. Stewart SD \& Menning CL (2009) Family structure, nonresident father involvement, and adolescent eating patterns. J Adolesc Health 45, 193-201.

71. Kaplan M, Kiernan NE \& James L (2006) Intergenerational family conversations and decision making about eating healthfully. J Nutr Educ Behav 38, 298-306.
72. Yeh MC, Ickes SB, Lowenstein LM et al. (2008) Understanding barriers and facilitators of fruit and vegetable consumption among a diverse multi-ethnic population in the USA. Health Promot Int 23, 42-51.

73. Currie C, Molcho M, Boyce W et al. (2008) Researching health inequalities in adolescents: the development of the Health Behaviour in School-Aged Children (HBSC) family affluence scale. Soc Sci Med 66, 1429-1436.

74. Braveman P (2006) Health disparities and health equity: concepts and measurement. Annu Rev Public Health 27, 167-194.

75. Gazmararian JA, Adams MM \& Pamuk ER (1996) Associations between measures of socioeconomic status and maternal health behavior. Am J Prev Med 12, 108-115. 